\title{
Contextual Factors Influencing Health Information Systems Implementation in Public Sector - Investigating the Explanatory Power of Critical Success Factors
}

\author{
Karin Axelsson and Ulf Melin \\ Department of Management and Engineering, \\ Linköping University, SE-581 83 Linköping, Sweden \\ \{karin.axelsson, ulf.melin\} @liu.se
}

\begin{abstract}
In this paper, we approach the field of critical success factors (CSF) by analyzing a successful case of IT implementation within the public health sector. The purpose of the paper is to gain further understanding of if and how well CSFs can explain a successful case. The main conclusion drawn is that even though the studied organization shows signs of common CSFs, this alone cannot explain the success. An important contribution from this study is thus the focus on contextual factors when trying to understand what makes an implementation project successful.
\end{abstract}

Keywords: health information system, IT implementation, public sector, critical success factors, contextual factors, project success.

\section{Introduction}

In this paper ${ }^{1}$, we approach the field of critical success factors (CSF) by analyzing a successful case of IT implementation within the public health sector. We have studied a University Hospital's implementation of an integrated health information system (HIS). During the longitudinal case study we came across one clinic which implementation process seemed to differ from many of the other clinics and care units [2]. This clinic was described by practitioners within the organization as very successful compared to many other units at this hospital. The impression of a success story made us curious to study this clinic in more detail to find out what made the process and result so different there. By understanding reasons behind the success we can analyze if CSFs potentially can explain the success, or if there are other explanations in this case. Based on our findings we discuss and question the maybe overestimated belief in CSFs as a "silver bullet" for success performance.

Heeks [13] discusses that many studies of HIS implementation have focused on successful cases and, thus, missed to learn from failures. We agree with Heeks' argument that there is a difference between design of HIS and the practice in a care

\footnotetext{
${ }^{1}$ This paper builds partially upon a conference paper [2] presented at European Conference on Information Systems in 2011, but the present paper has a somewhat different focus.
} 
unit that can relate to several aspects; such as information, technology, processes, objectives and values, staffing and skills, management systems and structures, and other resources [13]. These are examples of the contextual circumstances that we have to address when discussing success and failure in implementation processes [2]. Contextual factors are often addressed in information systems (IS) research as for instance situational, organizational, environmental, task, and technology characteristics that influence the outcome of an IS development project [15], and are emerging in CSF research [24]. A similar discussion about the importance of the context in HIS implementation is emphasized by Yusof et al. [32], who suggest an evaluation model for HIS that focus alignment between human, organization and technology. Important conditions for and barriers to the adoption of healthcare technology is also investigated and discussed [10], [28]. Despite Heeks' [13] call for studies of failures, we take a successful case as our point of departure in this paper, as we aim to compare this case and the reasons we find to explain the success with existing knowledge on CSFs. In order to focus on contextual factors, we apply a benefit perspective [9] when analyzing the case. We are not aiming to formulate CSFs from our case, as most studies of success stories do. The purpose of the paper is instead to gain further understanding of if and how well CSFs can explain a successful case. After this introduction, the paper is organized in the following way: In Section Two we discuss previous research on CSFs in IT implementation projects. The research approach is reported in Section Three. Empirical findings from our case are presented in Section Four and discussed in Section Five the findings are discussed. The paper is concluded in Section Six.

\section{Previous Research on Critical Success Factors}

One of the pioneers in CSF research, Rockart [26], describes critical success factors , as a guiding approach in the IS domain for managers to define the information needs in order to reach the objectives of the organization. Later on, CSFs were focused on identifying key factors important for successful behaviour [18], which is e.g. emphasized by a quote from Boynton and Zmud [6 p. 17]: "The CSF methodology is a procedure that attempts to make explicit those few key areas that dictate managerial or organizational success." Many authors have focused on describing and recommending certain actions and conditions under which success is more likely to occur. In parallel, CSFs have been criticized as offering over-simplified solutions that are difficult to realize in practice, since many contextual circumstances also influence the outcome [2], [5], [20], [29].

As described in [2], literature in the area of public sector IT projects as well as IT projects in general [23] reports on several sets of success factors. Gil-García and Pardo [11] as well as Ho and Pardo [14], have carried out extensive literature reviews of CSFs of IT projects in the public sector. Success factors mentioned are, for example, top management commitment, linkage to business, technical alignment, knowledgeable personnel, and user involvement [14]. The need to involve users in a sustainable way is also pointed out as a key issue by e.g. Chan and Pan [7]. Other scholars are focusing on CSFs in HIS implementation projects [21] and their findings 
are of a similar kind. CSFs, independently of source and context, tend to be alike. Thus, it does not seem to be evident differences between CSFs suggested for public or private sector. One interesting difference between public and private organizations, highlighted by Rosacker and Olson [27], is however that public organizations are considered as less competitive. This fact might be an important difference when discussing CSFs, since this implies that short-term incitements for change and innovation are lower in public organizations. This may be elaborated more on, but they argue that when applying CSFs in public sector each factor's dominance differs from findings in private sector (ibid.). Findings presented by Rocheleau and Wu [25] show that higher competition in private sector forces organizations to invest more resources in IT, compared to public organizations, in order to gain competitive advantage. However, they also find that public and private organizations rate IT as equally important, even though they spend fewer resources in IT (ibid.). This implies that despite varying degrees of competition between sectors, both public and private organizations aim to realize similar goals, such as increased coordination and efficiency, by implementing IT.

Berg [5] claims existing CSF lists to be challenging since success can be judged and structured in many dimensions; such as effectiveness, efficiency, organizational attitudes and commitment, employee satisfaction, and patient satisfaction. This is also discussed by Melin and Axelsson [20] investigating different images on HIS implementation challenging existing CSFs. This makes the guidance of successful practice more complex and CSF lists often offer a more simplified solution than what is actually needed in a "messy" real-life project. In order to illustrate the complexities of HIS implementation processes, Berg [5] investigates three myths related to such processes; implying that: (1) HIS implementation is a technical realization of a planned system in an organization, (2) HIS implementation can be left to the IT department, and (3) the implementation including the required organizational redesign can be planned. By scrutinizing these myths, Berg [5] concludes that HIS implementation is a mutual process where both organization and technology influence each other; a mutual process which has to be supported by both management and future users. The management of a HIS implementation process also implies an act of balance between initiating organizational change and using the HIS as a change agent without specifying and controlling this process too far [5].

CSF research includes identification and assessment of factors that might explain an organization's or a project's success [19]. In practice, CSF studies are often delimited to the identification of such factors, though [16]. There is a lack of CSF research which adopts a more holistic approach and analyzes how these factors can be handled in different contexts [24]. Remus and Wiener [24] imply that CSF research contributions to practice can be discussed and questioned, especially quantitative studies of success as the dependent variable. The authors are critical towards the idea of marketing CSFs as objective knowledge that is possible to adopt in any organization in order to easily handle challenges and reach goals. Remus and Wiener [24] argue that CSFs cannot be treated as instrumental, causal or objective. Instead, they view CSFs as being conceptual constructs that research and practice need to have dialogues about to find new perspectives (ibid.). Lau et al. [17] propose a framework of benefit evaluation where contextual factors that influence HIS adoption by clinicians are highlighted. They focus on the importance of handling people, 
organizational change and HIS implementation in a coherent way. Obviously, there are studies focusing contextual factors' relation to CSFs, but this kind of CSF research is still rather unusual [24].

An exception from this lack of a contextual focus is presented in an article by Doherty et al. [9], in which the authors claim that success in IT projects should be measured by its actual ability to deliver meaningful benefits, rather than applying factors that are said to facilitate successful outcome from IT projects. Doherty et al. [9] examined actionable factors that might lead to effective realization of benefits by studying three organizations. Benefit realization and benefit management is a vast research field [1], [31] which we do not intend to fully explore in this paper. Instead we use the findings from Doherty et al. [9] in order to investigate our case from a benefit perspective. Thus, we acknowledge the context when discussing success factors in our case. Doherty et al.'s result shows that a subset of traditional CFS might be improved in order to make them more focused on benefits realization. Their contribution is also formulated in a set of coherent principles [9]: (1) Benefit orientation - Explicit focus upon delivery of benefits in the organization is needed, (2) Organizational change - Benefits primarily come from organizational change rather than directly from technology, (3) Tailor to context - Every project is unique which implies that the specific organizational context must be acknowledged, (4) Factors are interdependent constructs - Success factors are not delivering success independently of each other but have to be managed altogether, (5) Investments have a lifecycle Projects' success might be realized long after the implementation project is ended, and (6) Portfolio focus - Success factors need to be applied to an organization's all systems, not only to one individual system, in order to be actionable (ibid.).

Doherty et al. [9] claim that these principles can be seen as themes upon which successful practices and factors can be established. We will, thus, return to these key principles later in the paper when discussing the empirical findings. We identify several reasons for using these key principles in our discussion. Doherty et al. [9] give voice to problems with CSFs which we also find relevant; (1) system development projects are seen as a static process neglecting the fact that factors may have varying importance in different phases of the project, (2) the context is often forgotten or assumed to be identical for many projects, (3) CSFs are seen as discrete independent variables which makes us miss interrelations between factors, and (4) CSFs are focused on a project which ends when a technical artefact is delivered (ibid.). Since Doherty et al.'s key principles try to handle these identified problems we find them useful to apply to our case. By doing so, we also contribute with an independent examination of the principles.

\section{Research Approach}

In this paper we analyzed a case study [2] performed in the public health sector. We have conducted a qualitative, interpretive study [30] of an implementation process of a HIS in a Swedish public health provider organization. The findings discussed in this paper are part of a larger longitudinal study of this implementation process that started in 2008 and ended in 2011 [20]. The theme (contextual factors and CSFs) focused in this paper was highlighted empirically during the summer 2010. The findings regarding this particular theme within the larger case are generated from two 
dedicated qualitative, face-to-face, semi-structured interviews. The interviews were audio recorded and each interview lasted for two hours. A qualitative interview guide was used, with a mix of pre-defined open questions and open ended questions, topics and informal communication [22]. We asked questions about the respondents' experiences before, during and after the change and implementation process as well as what aspects they found to be most important in this context. During the interviews we focused why this case is perceived as much more successful than the rest of the organization. The two respondents are both organization developers employed by the studied public health provider. The two persons were selected as they possess much information about the focused case. The first respondent works at the hospital's care process centre (CPC), which is the organizational unit responsible for the HIS implementation process, and the second respondent was involved in the process change and HIS implementation project at the studied clinic. The second respondent was suggested during the first interview, i.e., we used a snowball sampling method [22] to find this respondent.

The empirical data might seem limited in the above description, but it is important to remember that we have studied the organization longitudinally. Consequently, the empirical context of the focused interviews is informed by other interviews, studies of documents, field work and systems studies. We have conducted over 25 interviews in this organization. In this larger study the respondents were located in the CPC, in two public health centres and in two other hospital clinics. We have also studied documents; e.g. the health provider's website with information to patients, internal project documentation, budgets, external evaluation reports, and media's coverage of the project. This data triangulation implies that we have a thorough understanding of the organizational context as we have had access to the University Hospital for a long time.

\section{$4 \quad$ Empirical Findings}

The following presentation of empirical findings is based on a part of an earlier publication covering this case [2]. The implemented HIS comprises a widely integrated medical record for all care units in the University Hospital which implied an important change in the entire organization. Internally the project was characterized as the largest change project ever initiated. The specialist healthcare centres located at the hospitals in the region did not have any IT based medical record system before. They have had disparate systems before handling, e.g., schedules, lab results, etc., but no integrated HIS. The implementation process of the integrated COSMIC system (Compliant Open Solutions for Modern Integrated Care) started with a pilot involving a few care units and was then continued to all units in a rather fast pace. The implementation project followed a "big bang" approach from the perspective of each organizational unit, but a step by step initiative from the overall perspective. Thus, time was apprehended as the most important project goal to meet (compared to system functionality and cost).

The unit focused in this paper is the orthopaedics clinical department at the University Hospital. The clinic had changed the process for handling referrals prior to the implementation of the HIS. The main motive for this process change was the need 
to improve usage of resources and planning, but also an ambition to increase patient focus. Identified problems in the old process were huge volumes of patients combined with unsatisfactory routines, high degree of randomness, and lack of sufficient planning. Very persistent hierarchical levels and roles between professional groups are some reasons for change inertia in the organization until this process change was conducted. Much focus had been put on certain professions and organizational issues instead of focusing the patients and their needs for care. Prior to the HIS implementation there was also a lack of central governing instruments in the organization. The implementation of process changes followed by the HIS have resulted in a very successful integration of the system's prescribed functions for referral management and the new work processes, according to our respondents.

The change process started in a conflict between an organization developer (one of our respondents) at the studied clinic and one of her managers. The identified problems, mentioned above, were obvious to the respondent, but the manager did not agree about the problem definition. Nevertheless, the organization developer was asked to estimate possible capacity to handle patient referrals in better ways with existing resources. When she presented her results she did not receive any approval from the organization, but she continued her assignment anyway (like a skunk work process). More or less by a coincidence, the respondent also started to cooperate with a researcher specialized in optimization. The cooperation resulted in a thorough plan for capacity and resource optimization for the referral management at the clinic. Because of severe resistance the organization developer started working with manual referral management based on rough sorting of referrals. In parallel, clear guidelines for referral management and assessment were established. The critical voices in the organization did not stop, but our respondent continued to defend the new process. She also became responsible for controlling that the new guidelines for referral management were followed.

This process change took place before the implementation of COSMIC. The developed manual workflow model for the referral management process was later integrated in COSMIC without any problems, as the process logic in COSMIC were very similar to the manual process. This is regarded as an important reason for the successful ending of the change process; the system supporting institutionalization of the process. As the process was changed prior to the HIS implementation this cannot be seen as a planned result. The organization developer decided to act on her own initiative, following her own belief and step out of her formal role, addressing the needed process changes by direct facilitation on an operational level. The ideas behind the new process are not particularly innovative in general, but rather straight forward to implement and use. The notable fact is that the need to be innovative within the healthcare sector was acknowledged. Prior to the process change, the studied clinic's routines for referral management were unstructured and uncoordinated. Without process changes, the referral management built into the HIS would not have supported the organization. One of the organization developers describes this as: "We had to some extent already simulated COSMIC by manually distributing referrals and assessment responsibility between plastic boxes. When COSMIC was implemented, the system did function in exactly the same way." 
The plastic boxes, used for sorting and distribution of referrals based on medical diagnosis, were at a later stage easily modelled and implemented in the HIS and, hence, proved to be a successful alignment between the changed business process and the HIS functionality. Obviously, the studied clinic had started to think in new directions and question conditions that had been taken for granted before. The notion of overlapping competencies leading to efficiency, which has been a common view in the healthcare sector for a long time, was for example challenged. Instead, it was seen as more important to use existing resources in the most suitable way and actively recruit certain competencies. One of the most influencing changes in the studied process was the introduction of an explicit coordinator role. The coordinator is responsible for controlling the flow of referrals through the HIS and distributing them to the correct part of the clinic depending on required expert skills. This is put forth as an important new role by one of the organization developers: "We have introduced coordinators, this is very, very important. Now there are persons who are appointed to have this assignment."

Of course it might be easier to see positive changes afterwards, but it is obvious that the coordinator role is very important for the outcome of this change. Another critical factor is the distinct and in some aspect firm control that the clinic's management has conducted, as indicted by one of the organization developers: "The management has been really supportive - they have been very determined and told everybody that this is the way we shall handle the referrals from now on [...] please, staff each section according to this decision."

During the change process, conflicts related to the strict hierarchical organization and power structures associated with professional healthcare roles have been a recurrent challenge. The coordinator role was questioned since a "business generalist" got control of the flow instead of a skilled physician. This can, together with previous lack of central control instruments and unwillingness to change, be seen as inertia factors. The distinct change inertia might also be explained by lack of previous change processes. There was no experience of earlier change projects and many employees reacted negatively when the studied changes were presented. Our interpretation is that the organization was not ready to accept the change arguments in which positive consequences of increased patient focus and cooperation were emphasized. The hospital management used economic terms as incentives to handle this situation. If parts of the organization did not accept the new goals and processes they would be financially "disfavoured", as one of the organization developers expresses: "It is all about money - it always comes first. And it takes a strong leadership to have the courage to carry the ideas through. It is about understanding that we are responsible for a production that must be satisfying - it is not the resources in such that are going to be satisfied. You have to think the other way around."

\section{Discussion}

In table 1, below, we use Doherty et al.'s [9] key principles for successful benefit realization as a point of departure when discussing explanations of success in the studied case. 
Table 1. Mapping empirical success explanations to Doherty et al.'s [9] key principles

\begin{tabular}{ll}
\hline $\begin{array}{l}\text { Key } \\
\text { principles }\end{array}$ & $\begin{array}{l}\text { Explanation of } \\
\text { the principle }\end{array}$ \\
\hline $\begin{array}{l}\text { Benefit } \\
\text { orientation }\end{array}$ & $\begin{array}{l}\text { Explicit focus } \\
\text { upon delivery of } \\
\text { benefits in the } \\
\text { organization. }\end{array}$ \\
& \\
Organiza- & $\begin{array}{l}\text { Benefits } \\
\text { primarily come } \\
\text { tional } \\
\text { change }\end{array}$ \\
from \\
organizational \\
change rather \\
than directly \\
from technology. \\
Every project is \\
unique which \\
implies that the \\
cailor to \\
context \\
organizational \\
context must be \\
acknowledged.
\end{tabular}

Factors are Success factors interdepend are not delivering dent constructs

Investments

have a lifecycle

\section{success} independently of each other but have to be managed altogether. Projects' success might be realized long after the implementation project is ended.

Portfolio focus

\section{Empirical success explanations in the case}

The organization developer was a very committed key actor who believed in the process changes longitudinally. She continuously worked with and had the courage to fight for issues that she hoped would be beneficial for the organization. She was strongly supported by top and middle management, as they also focused on benefit realizations rather than e.g. to institutionalize power relations between actors within professional hierarchies.

The new referral process and the implemented HIS were aligned thanks to the fact that the organizational change took place before the HIS implementation. Organizational change was obviously explicitly emphasized as the main priority in the organization. The HIS implementation later took advantage of the process changes (the IT-process fit), and benefits were realized to a very high extent.

The persons controlling the referral flow made systematic assessments based on high expertise and good overview of the organizational processes and contexts. This process was designed thanks to the organization developer's deep understanding of the organizational context, which she and others in the project acknowledged during the process changes and HIS implementation. The fact that a rewarding, although rather ad hoc, cooperation with an external expert on optimization took place, is another example of how contextual aspects have been handled successfully in this case.

The persons involved in the project got an explicit change authority and were able to make decisions and approach problematic situations in the entire organization, in order to find a new way of handling the referral flow. As the case illustrates, several of the success explanations above are interlinked; e.g. the management support, the personal commitment and persistence to conduct changes that the organization would benefit from and the external expert knowledge that was brought into the project. Since the process changes in this case took place prior to the HIS implementation, one could argue that some benefits were realized already before the HIS was introduced. At least, this shows that the organization did not define the organizational change as a project with a pre-defined end. However, the real benefits from the HIS implementation occurred afterwards, when all personnel at the clinic used the HIS. If the referral process had not been redesigned before the HIS implementation, the benefits would have been limited due to a misfit between the process and the HIS.

In this case, the HIS was an integrated and enterprise-wide system which implied that the process and system changes truly influenced the whole organization. The successful approach was in that sense applied in the entire organization, even if dimensions also were left out in other implementation contexts within the organization. organization's all systems, not only to one individual system, in order to be actionable.

As mentioned earlier, these principles focus themes that can be usable when formulating successful practices and factors [9]. In this paper we do not intend to formulate any CSF. Instead, we apply the principles to our case in order to structure 
our findings around these themes. As can be seen in the table, the key principles cover our success explanations well. This illustrates that the usefulness of Doherty et al.'s theoretical construct is supported by the findings in our case.

The benefit orientation and the explicit focus upon delivery of benefits in the organization [9] are important aspects in this case. The studied organization succeeds in realizing substantial benefits from their HIS implementation thanks to recently made process changes. However, neither because of the software solutions in such nor because of the way the implementation project is carried out. The process change is not driven by or initiated in coherence with the HIS implementation. Nevertheless, this case is highlighted as a very successful example of HIS implementation in the studied University Hospital. An image of success is surrounding the case [20], and this image is not false as the case indeed shows a successful outcome. The results were not reached by following any CSF list to success. Instead, this situation can be compared to one of the myths that Berg [5] discusses; the belief that the HIS implementation including required organizational redesign can be completely planned. Berg proposes a balance act between initiating organizational changes and using the HIS as a change agent [5].The statement that benefits primarily come from organizational change rather than directly from technology [9] corresponds well to the role the HIS had in this case. The HIS did not have the role of a driving change agent, but it had a very important role for realizing the benefit of the change process in the end. The change process was driven by one person, but without support from strategic intentions in the organization. Thus, the reached fit between organization, human and technology [32] was not explicitly planned, it rather occurred during the process.

Every project is unique which implies that the specific organizational context must be acknowledged [9]. The case indicates that implementation of a HIS is not automatically creating success just by following a list of important fulfilment measures or CSFs. On the contrary, if the process of referral management had not been changed prior to the HIS implementation, the system would not have fitted into this organization. Croll [8] shows that for a HIS implementation to be successful it is of utmost importance that the HIS is accepted by the clinical users. In our case the improved referral process and its coherence with HIS led to system acceptance among the user groups. From the case, we cannot say that common CSFs such as top management commitment, linkage to business, technical alignment, knowledgeable personnel, and user involvement [14] alone would have led to success, even though we find signs of these dimensions in the case. Instead, the success can be explained by individual key persons' deep organizational understanding of the situation and commitment to their assignment, persistence and strong beliefs to achieve change [3] and to achieve this also challenging the barriers of implementing HIS in professional and hierarchical organizations with strong norms [10]. This is in line with Ashurst et al.'s (2008) conclusion that effective benefits realization demands an on-going commitment. This combined with a growing demand for organizational control and patient focus as well as top management's thorough governance was very important factors for performing successful change management.

The claim that success factors are not delivering success independently of each other but have to be managed altogether [9] stands in contrast with the ambition to 
help organizations to succeed in their daily tasks by creating road maps for success. Such lists of CSF have been very much adopted and appreciated in practice, but have also been criticized [24], [29]. The goal of standardizing and determining successful behaviour is not aligned to the notion of situational uniqueness and contextual differences as pointed out by many scholars [5], [9], [12], [13], [17], [24], [32].

Projects' success might be realized long after the implementation project is ended [9] which implies that patience is an important feature in this kind of project. This also relates to Doherty et al.'s [9] last principle, meaning that success factors need to be applied to an organization's all systems, not only to one individual system, in order to be actionable. In the studied case process development was conducted, which challenged established and institutionalized hierarchies and powerful professional groups. Without being able to handle the hierarchical conflicts between professions or overcoming the change inertia in the studied organization, no set of CSFs would have solved the situation. One could argue that handling these challenges was part of this organization's unique signature [12] that made it successful. Understanding the uniqueness of each organizational unit is critical in order to succeed transferring this success to other care units in the future. What worked in this case does not necessary have to be the key to success in next case.

\section{Conclusions}

In this paper we have examined if and how well CSFs can explain a successful case of HIS implementation. CSFs have been criticized by many as neglecting the contextual circumstances, which we have discussed earlier in the paper. We adhere to these raised objections and have therefore applied Doherty et al.'s [9] key principles when structuring and analyzing findings from the case. At a first glance one might think that these key principles are yet another set of success factors. However, Doherty et al. [9] are aware of the mentioned problems with CSFs and have formulated their principles in a way that acknowledges contextual factors when evaluating benefit realization.

Our main conclusion is that even though our case shows signs of common CSFs, this alone cannot explain the success. The implemented HIS offered the appropriate functionality, but the organization would not comply voluntarily. The success in our case can instead be explained by the fact that contextual circumstances were handled in a beneficial way by a strongly committed and persistent organization developer who, in a way, created her own implementation plan as a skunk work and proved to be strong enough to contest the old professional hierarchies. This encourages us to argue that contextual factors are very critical to understand and acknowledge during HIS implementations. This is supported by Beeuwkes Buntin et al.'s [4] literature review of HIS benefits, where human aspects are critical to successful HIS implementation. A similar reasoning is made by Remus and Wiener [24] who call for further studies of CSFs from this wider perspective. We also believe that key factors in this case have been a history of local empowerment and organizational stability [2]. The lack of organizational change experience might, to a great extent, have caused employees to react negatively on change initiatives whatever the cause was. 
Even though we have studied HIS implementation in this paper, we argue that our findings could be expanded to other IT implementation settings and sectors as well. Of course there are some characteristics that may distinguish the health sector from other sectors; such as strong professional roles, explicit hierarchies, specialized expertise, and certain laws and regulations, but we argue that the result to some extent is valid also when implementing other IT systems than HIS. However, since our main point in this paper is the importance of understanding contextual circumstances, it is important to acknowledge such uniqueness. The contextual circumstances might differ between sectors (otherwise they would not be contextual) and particular organizations and settings within them, but we argue that the context needs to be acknowledged in any IT implementation process. The fact that our explanations of success in the studied case were possible to map to Doherty et al.'s [9] key principles is another argument for the claim that our results could be useful also in other IT implementation situations outside the healthcare sector, and that analytical generalization potentially can be done.

This paper reports from a single case study. We have used the case to understand if and how well CSF can be used to explain success. In order to develop a complete picture we will study and compare further cases, preferably implementation, IT and organizational cases with a large variation.

Acknowledgements. This study has been financed by the Swedish Council for Working Life and Social Research. We are also grateful to Fredrik Söderström for his data collection effort.

\section{References}

1. Ashurst, C., Doherty, N.F., Peppard, J.: Improving the impact of IT development projects: the benefits realization capability model. European Journal of Information Systems 17(4), 352-370 (2008)

2. Axelsson, K., Melin, U., Söderström, F.: Analyzing best practice and critical success factors in a health information system case - are there any shortcuts to successful IT implementation? In: Tuunainen, V., Nandhakumar, J., Rossi, M., Soliman, W. (eds.) Proceedings of the 19th European Conference on Information Systems, Helsinki, Finland, pp. 2157-2168 (2011)

3. Beath, C.M.: Supporting the information technology champion. MIS Quarterly 15(3), 355$372(1991)$

4. Beeuwkes Buntin, M., Burke, M.F., Hoaglin, M.C., Bluemnthal, D.: The benefits of health information technology: a review of the recent literature shows predominantly positive results. Health Affairs 30(3), 464-471 (2011)

5. Berg, M.: Implementing information systems in health care organizations: myths and challenges. International Journal of Medical Informatics 64(2-3), 143-156 (2011)

6. Boynton, A.C., Zmud, R.W.: An assessment of critical success factors. Sloan Management Review 25(4), 17-27 (1984)

7. Chan, C.M.L., Pan, S.L.: User engagement in e-government systems implementation: a comparative case study of two Singaporean e-government initiatives. Journal of Strategic Information Systems 17(2), 124-139 (2008) 
8. Croll, J.: Testing for usability is not enough: Why clinician acceptance of health information systems is also crucial for successful implementation. In: Takeda, H. (ed.) EHealth 2010. IFIP AICT, vol. 335, pp. 49-60. Springer, Heidelberg (2010)

9. Doherty, N.F., Ashurst, C., Peppard, J.: Factors affecting the successful realization of benefits from systems development projects: findings from three case studies. Journal of Information Technology 27(1), 1-16 (2012)

10. Fichman, R.G., Kohli, R., Krishan, R.: The role of information systems in healthcare: current research and future trendes. Information Systems Research 22(3), 419-428 (2011)

11. Gil-García, J.R., Pardo, T.A.: E-government success factors: mapping practical tools to theoretical foundations. Government Information Quarterly 22(2), 187-216 (2005)

12. Gratton, L., Ghoshal, S.: Beyond best practice. MIT Slone Management Review 46(3), 4957 (2005)

13. Heeks, R.: Health information systems: failure, success and improvisation. International Journal of Medical Informatics 75(2), 125-137 (2006)

14. Ho, J., Pardo, T.A.: Toward the success of e-government initiatives: mapping known success factors to the design of practical tools. In: Proceedings of the 37th Hawaii International Conference on Systems Sciences, pp. 1-6. IEEE (2004)

15. Kearns, G.S., Sabherwal, R.: Strategic alignment between business and information technology: a knowledge-based view of behaviors, outcome, and consequences. Journal of Management Information Systems 23(3), 129-162 (2006)

16. Kuang, J., Lau, J., Nah, F.: Critical factors for successful implementation of enterprise systems. Business Process Management Journal 7(3), 285-296 (2001)

17. Lau, F., Price, M., Keshavjee, K.: From benefits evaluation to clinical adoption: making sense of health information system success in Canada. Healthcare Quarterly 14(1), 39-45 (2011)

18. Leidecker, J., Bruno, A.: Identifying and using critical success factors. Long Range Planning 17(1), 23-32 (1984)

19. Leimeister, J.M., Sidiras, P., Krcmar, H.: Success factors of virtual communities from the perspective of members and operators: an empirical study. In: Proceedings of the 37th Hawaii International Conference on System Sciences (HICSS), Hawaii, USA (2004)

20. Melin, U., Axelsson, K.: Implementing Healthcare Information Systems - Mirroring a Wide Spectrum of Images of an IT Project. Health Policy and Technology 3(1), 26-35 (2014)

21. Øvretveit, J., Scott, T., Rundall, T.G., Shortell, S.M., Brommels, M.: Improving quality through effective implementation of information technology in healthcare. International Journal for Quality in Health Care 19(5), 259-266 (2007)

22. Patton, M.Q.: Qualitative evaluation methods. Sage Publications, Beverly Hills (1980)

23. Reel, J.S.: Critical success factors in software projects. IEEE Software, 18-23 (May/June 1999)

24. Remus, U., Wiener, M.: A multi-method, holistic strategy for researching critical success factors in IT projects. Information Systems Journal 20(1), 25-52 (2010)

25. Rocheleau, B., Wu, L.: Public versus private information systems: do they differ in important ways? A review and empirical test. The American Review of Public Administration 32(4), 379-397 (2002)

26. Rockart, J.F.: Chief executives define their own data needs. Harvard Business Review 57(2), 81-93 (1979)

27. Rosacker, K.M., Olson, D.L.: Public sector information system critical success factors. Transforming Government: People, Process and Policy 2(1), 60-70 (2008) 
28. Venkatesh, V., Xiaojun, Z., Sykes, T.A.: 'Doctors do too little technology': a longitudinal field study of an electronic healthcare system implementation. Information Systems Research 22(3), 523-546 (2011)

29. Wagner, E., Scott, S., Galliers, R.: The creation of 'best practice' software: myth, reality and ethics. Information and Organization 16(3), 251-275 (2006)

30. Walsham, G.: Doing interpretive research. European Journal of Information Systems 15(3), 320-330 (2006)

31. Ward, J., Daniel, E.: Benefits management - delivering value from IS and IT investments. John Wiley and Sons Ltd, Chichester (2006)

32. Yusof, M.M., Kuljis, J., Papazafeiropoulou, A., Stergioulas, L.K.: An evaluation framework for health information systems: human, organization and technology-fit factors (HOT-fit). International Journal of Medical Informatics 77(6), 386-398 (2008) 